\title{
The Process of the Introduction of Western Punctuation System Into China and Its Influence
}

\author{
Xinxin Zhang ${ }^{1, a}$
}

\author{
${ }^{1}$ Beijing National Day School, Beijing, China \\ ${ }^{a}$ Author's Email: Zhangxinxin_cici@sina.cn
}

\begin{abstract}
The punctuation system existed both in ancient China and ancient Europe, but compared with the relatively complete and unified European punctuation system, the system of punctuation in ancient Chinese was not uniform, and there is not a national standard generally agreed way of use. In the West, to be more exact, in the European countries, the birth of punctuation marks actually also exists a process of gradual unification. This paper analyzes the process of the introduction of the western punctuation system into China and its influence.
\end{abstract}

Keywords: Cultural exchange, Cultural communication, Language, Punctuation mark system

\section{INTRODUCTION}

Punctuation is the use of spacing, conventional signs, and certain typographical devices as aids to the understanding and correct reading of the written text, whether reading silently or aloud. It is the practice, action, or system of inserting points or other small marks into texts in order to aid interpretation, division of text into sentences, clauses, etc., by means of such marks. In fact, most people believe that China only introduced punctuation marks as one of the forms of official written expression in modern times (after 1840), and punctuation marks were introduced from the western literary system and were introduced into China, which is a product of foreign culture. But in fact, in the ancient pre-Qin period (before 221B.C. ), there had been punctuation marks in ancient China, as well as the ways and rules of its use.

\section{THE HISTORY OF PUNCTUATION BEFORE MODERN HISTORY IN CHINA}

In a copy samples of Laozi, a calligraphy work in the pre-Qin period (before 221 B.C.), most of the calligraphy samples have circular punctuation marks at the end of sentences. In these calligraphy examples, punctuation marks are used to separate two different sentences. Some scholar-officials in the Qi dynasty used one or two short lines to represent heavy prose and punctuation marks to separate two different sentences. Of course, the punctuation marks in samples of ancient
Chinese funeral writings are relatively simple, with only one mark indicating the space between sentences. "During the Han Dynasty, there were specific words to describe the pauses between sentences and the end of sentences, which is called "Judu". It is usually written by placing two words between two sentences, or by using a vertical or dash line to mark the end of a sentence. "[1]In the Qing Dynasty, the use of punctuation in ancient China had been entered the mature period and had a more standardized use method. In the punctuation usage norms issued by the Qing Dynasty, a large number of western punctuation systems existed, and their usage was consistent with that of European punctuation systems. During the Qing Dynasty, due to the war and the colonial invasion of a large number of European countries on China, a large number of foreign cultural products flowed into China, which had a quite extensive impact on Chinese culture. Therefore, the punctuation standards of these officials are influenced by western culture, and these so-called punctuation marks cannot be called the punctuation system developed in native China.

But in fact, in ancient China, books with punctuation marks were always in the minority, and punctuation was often expressed in a specific way. A large number of books without any punctuation existed in ancient times. For these books, there is often a particular way of representing punctuation. These expressions usually depend on the reader's sense of language and familiarity with mood particles and grammatical structures. There are special words used to indicate the end of a sentence. 
For example, "the "Poetry", the collection of poems in ancient China, used repeated forms and neat sentences, and the "Sao", a poetry written in pre-Qin period, used "xi" to indicate the end of a sentence."[2][3]However, to have a sense of language and to learn mood particles, grammatical structures need to be learned through a specific cultural language, and a sense of language actually depends on the experience of a lot of reading. These increased the process of cultural communication, increased the difficulty for the poor class to get in touch with a large number of cultural products, deepened the cultural barriers, and increased the wider dissemination of literary books to a certain extent. At the same time, this complicated method to distinguish sentence patterns is also the reason why there are some misunderstandings in ancient literature. In the process of reading, "ambiguity often appears, resulting in a misunderstanding of the words and sentences of the articles". This also deepens the dilemma that literary and cultural products cannot be spread in a large range.

But even if punctuation existed in ancient China, plenty of books used it and the crux of the problem was that the punctuation system was not uniform. "Almost everyone uses one system, but there are barriers between each other's punctuation systems, and it is impossible to understand the usage methods and standards of each other's punctuation systems."[4]As a result, many parts of the text are incomprehensible. Given the chaotic background of such a punctuation system, and the urgent need for a simple and easy-to-understand way to facilitate people's understanding of sentences in literature, the ancient Chinese punctuation system would be deeply influenced by the western (to be more precise, European) punctuation system. To put it simply, firstly, there is no systematic, unified and stable punctuation system in China. Secondly, the language structure of Chinese requires that some simple symbols be used to represent the gaps between languages so that people can better understand the example sentences.

\section{THE HISTORY OF PUNCTUATION IN ANCIENT EUROPE}

Western punctuation originated in ancient Greece, most texts were still written in scriptura continua without any separation between words. "However, the Greeks were sporadically using punctuation marks consisting of vertically arranged dots-usually two (dicolon) or three (tricolon) — in around the 5th century B.C. as an aid in the oral delivery of texts." [5]After 200 B.C., the Greeks used Aristophanes of Byzantium's system (called théseis) of a single dot (punctus) placed at varying heights to mark up speeches at rhetorical divisions.

After the development of punctuation in the Middle Ages and later periods, the use of punctuation in
European countries is gradually approaching maturity. Manusius (about 1450 1515), the Italian grammarian and publisher who was the founder of the new punctuation system in the West, began to revise and innovate the existing punctuation system in the West. From the 15 th century to the early 18 th century, punctuation in English was called "pointing", which is different from modern punctuation, but more to show the direction of the language. And the word "punctuation," first recorded in the mid-16th century, is used in Hebrew texts for the insertion of vowels (marks near consonants that indicate before and after vowels). The two words exchanged meanings between 1650 and 1750. He replaced the rules of reading with the rules of grammar and established five types of printed punctuation: comma (,), semicolon (;). . Colon (:) Period (.) Question mark (?) ." Manusius has published nearly a thousand books over the past 100 years, which has sold well throughout Europe. These basic punctuation marks have become widely used in all languages.

Under such social, historical and social context, the use of punctuation marks in several countries of Europe is basically in a stable state. One is that the cultural background of most European countries is similar. There are no cultural barriers between each other, and the way of cultural transmission is relatively easier. At the same time, the standardized and generalized punctuation system has played a catalytic role in the dissemination of European literary works and culture, making it more convenient for readers to understand the contents of these documents, and deepening their understanding and familiarity with the use methods of punctuation system.

\section{THE PROCESS OF CHINESE BEING INFLUENCED BY THE WESTERN PUNCTUATION SYSTEM}

China was influenced and impacted by western culture can be traced back to the beginning of modern times, the Opium War in 1840. Through war terms, cession and colonization, the West began to import a large number of Western products into China, including religious and cultural products and other cultural products. And these cultural products have caused a serious impact on some cultural products and other ideological and literary products in China. After the shock, the Qing government, which was suppressed in all aspects of economy, politics and military, realized the significant differences in strength and culture between China and the West. Thus, it launched the Westernization Movement and introduced Western military equipment, machine production and science and technology to save the Qing Dynasty. At the same time, a large number of outstanding students of the Qing Dynasty were sent to the West and Japan to learn advanced culture and foundation, which provided a 
more powerful labor resource for the country when they returned to China.

Later, Zhang Deyi, a student of Tongwen University in the 7th and 8th years of Tongzhi (1868-1869) of the Qing Dynasty, was the first person to introduce punctuation marks from abroad and brought the complete punctuation system from the West back to China. In fact, he was one of the first batches of English and foreign language talents trained by the Qing government during the Westernization Movement. During his overseas study, he recorded a large number of western cultural customs and traditions, including the punctuation system, which had a profound influence on the later literary and cultural works in China.

After Zhang Deyi introducing the punctuation system into China, the content of the punctuation system in his works was also recognized and concerned by a large number of domestic scholars because his records were widely spread as precious materials. A large number of scholars have realized that there is a simple symbol system in the West that is convenient for the understanding of literary works, and that this symbol system does not have any linguistic and cultural barriers to hinder people's understanding of literary works. Chinese scholars focus on punctuation marks so as to promote the domestic for punctuation and symbol systems use to further advance, and in some published books of Qing dynasty, some special teaching abroad Qing westernization movement of elite tutorials on how to better use of punctuation marks is mentioned at the beginning of the Qing government to use standard punctuation.

At the time, the Qing government, however, has gradually lost domestic power control in the face of overwhelming western plunder, awakening people's patriotic spirit and the spirit of revolt against imperialism, colonialism. The Qing government made the corresponding series of including punctuation using standard literature lose the ability to spread, turning out to be only for foreign language talents abroad reference literature, rather than becoming one of the important materials that influence the development of Chinese literature.

Scholars in China did not stop paying attention to and promoting punctuation marks. After realizing that punctuation marks would have a strong influence on the domestic culture, the Preparatory Committee for the Unification of the National Language, an organization affiliated with the Ministry of Education to promote the national language, was established during the period of the Beiyang Government and the Nationalist Government put forward the Proposal for the Implementation of New Punctuation Mark. Under the existing domestic punctuation standards, this proposal refers to the use of standards of punctuation marks in various countries and basically takes the western punctuation system as the standard to propose a punctuation system suitable for China. Compared with the Chinese punctuation system that appeared in various literatures in the past, it solves the uniqueness and one-sentence pattern of the Chinese punctuation system in the past and enriches the diversity of the expression forms and meanings of punctuation marks. Besides, the old symbol of a circle and a dot, though very imperfect, is still very useful. When the legal knowledge of this text did not popularize, this simple symbol seems to be indispensable. Therefore, in this case, the use of these two symbols is also carefully separated, another called "old-style dot symbol". Attached at the back for scholars' reference." After this proposal, Mr. Hu Shi published the article On Sentence Reading and Character Symbols in Science, the most popular paper newspaper in China at that time. Due to the large reading flow and audience of paper media, this article On Sentence Reading and Character Symbols was widely spread in China. The concept and usage of punctuation marks have been widely spread in China and have caused a considerable impact on the cultural products of Chinese characters. After that, China has a widely circulated, and the content of the formal, the coverage of a wide range of punctuation marks issued using standard copy.

On February 2, 1920, the Beiyang government, which was the most dominant at that time, "approved a series of proposals and applications of the Preparatory Committee for the Unification of the National Language under the background of a wide audience and the previous proposals of the Preparatory Committee for the Unification of the National Language.'[6] In addition, the Ministry of Education of Beiyang Government issued Deception No. 53: Deception on the Use of New Punctuation Signs, which approved the Proposal for the Implementation of New Punctuation Signs jointly proposed by six professors headed by $\mathrm{Hu}$ Shi, including Qian Xuantong, Liu Fu, Zhu Xizu, Zhou Zuoren and Ma Yuzao, and promulgated the adoption of ". ; :? ! () "" and other punctuation marks. These marked the birth of China's first legal new punctuation marks. After that, China officially had a set of unified, complete and easy to implement punctuation systems, ending the chaotic and diverse punctuation system since the pre-Qin period, and completing the unity and simplicity of language. At the same time, the expression of punctuation marks in literary works can better help readers understand the content and deep meaning that the author wants to express in the text, and avoid a series of problems that lead to contradictions, such as single narration and ambiguity.

\section{CONCLUSION}

Both ancient China and Europe had relatively independent punctuation systems. However, compared 
with the concise punctuation system which is becoming more and more complete and unified in Europe, the punctuation system in ancient China is not unified all the time, and the usage method cannot be unified in the whole country. These problems, therefore, affect the maturity of Chinese localized punctuation marks. Due to the wars and the colonization of European countries in modern China, the Chinese punctuation system was influenced by the European punctuation system. Moreover, in modern times, through the efforts of some scholars, western punctuation marks were quoted and standardized, and some local punctuation marks were fused to form the present unified new punctuation system of China.

\section{ACKNOWLEDGMENT}

I am very grateful to the professor and the teaching assistant for their intellectual support in the cultural exchange between China and the West during the course period. It is precisely because this series of courses that my interest in the influence of cultural exchange and collision between China and the West have been aroused that I have completed the research on punctuation marks.

\section{REFERENCES}

[1] A brief introduction of the development history of Chinese punctuation byLiu Wei, Hou Minji and Xu
Xingsheng. Journal of Language and Literature Studies.23(2010):16-18.

doi:CNKI:SUN:YWXK.0.2010-23-008.

[2] Zhang Guizhen. Skills of punctuation and sentence reading in classical Chinese [J]. Time Education, 2017(08):36-46.

[3] So.gushiwen.org (in Chinese). Retrieved 12 February 2019.

[4] Sun Kun. Punctuation Features and Creative Ideas of Ancient Chinese Prose: Comparison with European Punctuation Tradition [A]. China Association for Comparative Studies of English and Chinese (CACSEC) ). The 11th National Symposium of the China-English-Chinese Comparative Research Association and the 2014 International Symposium on English-Chinese Comparison and Translation [C]. China Association for Comparative Studies of English and Chinese:2014:2.

[5] E. Otha Wingo, Latin Punctuation in the Classical Age (The Hague, Netherlands: De Gruyter, 1972), 22.

[6] Yuwen Hou. The process of introduction of punctuation in China.[J].Gansu Education, 2013(07):72. 